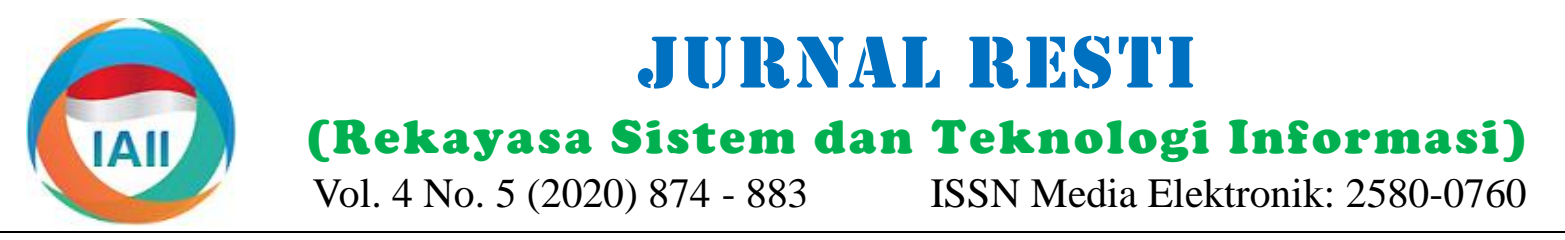

\title{
Implementasi Haversine Formula untuk Pembuatan SIG Jarak Terdekat ke RS Rujukan COVID-19
}

\author{
Chandra Husada $^{1}$, Kristoko Dwi Hartomo ${ }^{2}$, Hanna Prillysca Chernovita ${ }^{3}$ \\ 1.2.3 Jurusan Sistem Informasi, Fakultas Teknologi Informasi, Universitas Kristen Satya Wacana \\ 1682016012@student.uksw.edu, ${ }^{2} \mathrm{fti} @$ uksw.edu
}

\begin{abstract}
Haversine formula-based GIS has been created to find closest location to referral hospital handling COVID-19 in Semarang City. The objectives of this study were (1) to determine closest distance and compare the results with the calculation of Find Nearest Tool and Google Maps and (2) to design GIS. It was done through (i) primary and secondary data creation and processing, (ii) accuracy measurement using Haversine formula. GIS is built after the calculation results are obtained. Calculation of the distance from user's starting point to referral hospital can be generated using Haversine formula. Comparison of measurement results between Haversine formula-based GIS and Find Nearest Tool, the average differences is 13 meters, the smallest difference is 3 meters and the largest difference is 40 meters. The differences between the calculation results of Haversine formula and Google Maps, the smallest difference is 0 meters, the largest difference is 5 meters, and the average differences is 3 meters. GIS creation obtained through designing use case, activity, class diagram, and user interface. The conclusion is Haversine formula-based GIS can be used as "Geographic Information System for the Search of Referral Hospital Handling COVID-19 in Semarang City" based on the closest distance from user's location.
\end{abstract}

Keywords: haversine formula, closest distance measurement, referral hospital for COVID-19, geographic information system

\begin{abstract}
Abstrak
Telah dibuat Sistem Informasi Geografis (SIG) berbasis Haversine formula untuk pencarian lokasi terdekat rumah sakit rujukan penanganan COVID-19 di Kota Semarang. Tujuan penelitian ini, yaitu (1) menentukan jarak terdekat dan membandingkan hasil tersebut dengan hasil perhitungan Find Nearest Tool dan aplikasi Google Maps dan (2) merancang bangun sebuah SIG. Untuk pencapaian tujuan penelitian tersebut, dilakukan melalui (i) pembuatan data primer dan sekunder dan pengolahan data, (ii) pengukuran tingkat keakuratan dengan Haversine formula, maka perlu dibandingkan terhadap Find Nearest Tool maupun aplikasi Google Maps. Sistem Informasi Geografis dibangun setelah diperoleh hasil perhitungan berdasarkan jarak terdekat dari lokasi user. Berdasarkan penerapan Haversine formula dapat dihasilkan perhitungan jarak dari titik awal lokasi user menuju rumah sakit rujukan. Perbandingan hasil pengukuran jarak lokasi terdekat antara SIG hasil rancangan berbasis Haversine formula dan Find Nearest Tool diperoleh nilai selisih rata-rata sebesar 13 meter, dengan nilai selisih terkecil 3 meter dan nilai selisih terbesar 40 meter. Selain itu terdapat juga selisih antara hasil perhitungan berbasis Haversine formula terhadap hasil pengukuran jarak garis lurus dengan aplikasi Google Maps, dengan nilai selisih terkecil 0 meter dan nilai selisih terbesar 5 meter, sehingga nilai selisih rata-rata sebesar 3 meter. Pembuatan SIG juga telah diperoleh melalui rancang bangun use case, activity, dan class diagram yang dilengkapi dengan user interface. Berdasarkan hasil tersebut dapat disimpulkan, bahwa pembuatan SIG berbasis Haversine formula dapat digunakan sebagai "Sistem Informasi Geografis Pencarian Rumah Sakit Rujukan Penanganan COVID-19 di Kota Semarang” berdasarkan jarak terdekat dari lokasi user.
\end{abstract}

Kata kunci: formula Haversine, pengukuran jarak terdekat, rumah sakit rujukan CoViD-19, sistem informasi geografis.

\section{Pendahuluan}

Beberapa penelitian tentang pencarian jarak terdekat pernah dilakukan $[1,2,3]$. Algoritma Bellman-Ford digunakan pada salah satu penelitian untuk pencarian rute terpendek guna pengambilan sampah di Kota Palembang [1]. Kemungkinan keberadaan cost yang dikeluarkan dalam penentuan jalur pengambilan sampah dapat diantisipasi, karena bobot negatif pada nilai edge dapat ditemukan dengan algoritma Bellman-Ford. Pentahapan pada penelitian ini berupa análisis kebutuhan data, perancangan, implementasi, dan pengukuran kinerja sistem. Algoritma Bellman-Ford pada penelitian tersebut berhasil diimplementasikan dalam penentuan rute dari titik awal (lokasi sopir) ke

Diterima Redaksi : 03-08-2020 | Selesai Revisi : 10-10-2020 | Diterbitkan Online : 30-10-2020 
titik akhir (lokasi TPA) dengan nilai cost berupa jarak lainnya yaitu lebih akurat, tingkat error rendah dalam minimum, namun tidak dijamin untuk semua titik yang kecepatan analisa, dan juga perhitungan lebih mudah dilalui oleh sopir sebelum titik akhir dicapai [1].

Penelitian lain dengan implementasi Haversine formula digunakan untuk pembuatan SIG yang digunakan untuk bantuan kepada Badan Pertanahan Nasional (BPN) dalam pengukuran luas tanah [2]. Bentuk bidang dan luas tanah dapat ditampilkan pada sistem tersebut. dengan $d=$ jarak, $r=$ radius bumi sebesar $6371,1 \mathrm{~km}, \varphi \mathrm{x}$ Implementasi Haversine formula pada penelitian ini dan $\varphi y$ merupakan bujur (latitude) dalam radian, $\lambda \mathrm{x}$ dan digunakan untuk pencarían jarak antara dua titik dengan $\lambda y$ merupakan lintang (longitude) dalam radian, $\Delta \varphi$ derajat kelengkungan bumi diperhitungkan. adalah besaran perubahan bujur (latitude), dan $\Delta \lambda$ adalah Berdasarkan hasil penelitian tersebut dijelaskan, bahwa besaran perubahan lintang (longitude) [7]. Persamaan terdapat selisih pengukuran sebesar 3,33\% jika Haversine digunakan berdasarkan spherical earth dibandingkan terhadap Global Positioning System (GPS) (berdasarkan bumi bentuk), dengan elipsodial factor dan 7,33\% jika dibandingkan terhadap pengukuran (faktor karena bentuk bumi sedikit elips) diabaikan [8]. manual. Sistem tersebut merupakan bentuk kemudahan Ini adalah kasus khusus dari persamaan umum dalam bagi pegawai BPN dalam pengukuran luas tanah [2].

Topik penelitian tentang pencarian lapangan futsal di Kota Samarinda yang didasari oleh keberadaan lebih dari 20 lapangan futsal, namun minim dalam informasi lokasi, biaya sewa, dan kondisi lapangan. Para calon pengguna kesulitan dalam pemilihan lapangan futsal terbaik dan sesuai dengan kebutuhan. Permasalahan tersebut merupakan penyebab sejumlah lapangan futsal dengan lokasi jauh dipilih oleh beberapa pengguna. Diperlukan sebuah sistem untuk penyajian informasi tentang lapangan futsal yang dilengkapi fasilitasi fitur pencarian lapangan dengan jarak terdekat. Hasil penelitian ini dijelaskan, nahwa pemanfaatan Haversine formula dapat digunakan untuk penentuan jarak terdekat dengan cara penentuan hasil dengan nilai paling kecil sebagai lokasi terdekat [3].

Sejumlah konotasi pada gagasan tentang jarak dalam SIG dengan peranan penting dalam keputusan spasial untuk kehidupan yang dipengaruhi oleh rasa kedekatan dari satu objek terhadap objek lain. Berbagai objek spasial dapat dihubungkan oleh pengukuran jarak sebagai salah satu ukuran metrik. Hubungan topologis antara objek ditanamkan dari pengukuran jarak dan dapat diberikan sebuah gambaran seberapa dekat atau seberapa jauh objek tersebut dari objek lain. Jarak antar objek spasial dapat diukur dengan berbagai cara yang berbeda, karena terdapat banyak definisi dan ukuran yang berbeda tentang jarak. Beberapa ukuran jarak yang dihitung dengan SIG diantaranya, jarak spasial, jarak planimetrik, jarak kumulatif, jarak geodesi, dan sebutan lain. Persamaan untuk perhitungan masing-masing jarak berbeda-beda, sehingga hasil dari pengukuran jarak juga tergantung pada datum, sistem koordinat, dan sistem proyeksi yang digunakan [4].

trigonometri bola terkait dengan sisi dan sudut segitiga bola [9]. Tahapan cara kerja persamaan tersebut dapat dijelaskan dalam bentuk bagan alir. Bagan alir proses pada Haversine formula, seperti ditunjukkan pada Gambar 1.
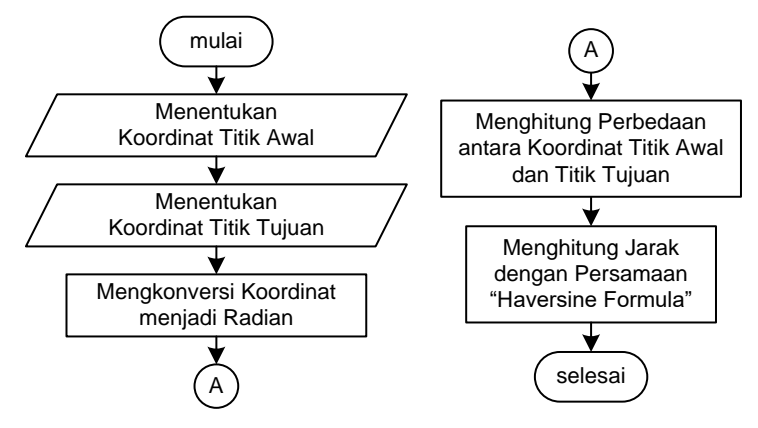

Gambar 1. Bagan alir proses pada Haversine Formula

Sistem Informasi Geografis (SIG) merupakan suatu sistem dengan unsur informasi geografis lebih ditekankan. Pengertian terkandung dalam istilah "informasi geografis" merupakan sebuah pengetahuan tentang posisi dari sebuah objek yang berada di permukaan bumi, disertai informasi tentang keterangan atau atribut dari objek tersebut [10]. Terdapat dua jenis data digital geografis, yaitu data spasial dan data nonspasial. Data spasial, adalah data yang berisikan informasi geografis atau sebuah lokasi dari suatu objek di permukaan bumi [11], sedangkan data non-spasial atau data atribut, adalah data yang berisikan atribut dari pernampakan-pernampakan di permukaan bumi [10]. Subsistem dari SIG, yaitu (1) data input sebagai tahap dalam persiapan dan pengumpulan data spasial dan nonspasial, (2) data output sebagai tahap pengeluaran seluruh atau sebagian hasil dari basis data, (3) data Persamaan Haversine adalah salah satu persamaan yang management sebagai pengorganisasian data ke basis penting dalam navigasi, yang dapat digunakan dalam data, agar data tersebut mudah untuk dipanggil, pencarian jarak antara dua titik pada permukaan bumi diperbaiki, dan diberbaharui, dan (4) data manipulation berdasarkan garis latitude dan garis longitude [5]. and analysis sebagai tahap penentuan informasi yang Beberapa kelebihan yang dimiliki Haversine formula dapat dihasilkan oleh sebuah SIG [12].

jika dibandingkan dengan perhitungan jarak geodetic 
Berpedoman kepada sejumlah hasil penelitian rumah sakit rujukan penanganan COVID-19 di Kota sebelumnya yang berkaitan dengan perolehan jarak Semarang tersebar di berbagai wilayah. Informasi terdekat ke suatu lokasi, maka pada penelitian ini tentang jarak lokasi rumah sakit rujukan tersebut sangat dirancang bangun sebuah SIG untuk pencarian lokasi minim, sehingga masyarakat kesulitan dalam penentuan terdekat rumah sakit rujukan penanganan COVID-19 di rumah sakit rujukan terdekat dari lokasi keberadaan Kota Semarang berbasis Haversine formula. Untuk calon pasien. Keberadaan permasalahan tersebut dapat perolehan hasil perhitungan, maka dilakukan sebagai penyebab masyarakat datang ke rumah sakit perbandingan terhadap hasil Find Nearest Tool dan rujukan dengan letak yang jauh, sehingga menjadi Google Maps. Keberadaan SIG sangat diperlukan, kurang efektif.

karena jumlah penduduk Kota Semarang pada tahun 2018 tercatat sebanyak 1.786 .114 jiwa [13] disertai mobilitas penduduk sangat tinggi, sehingga dapat sebagai penyebab peningkatan risiko penyebaran infeksi COVID-19. Hal ini dibuktikan dengan angka kasus positif COVID-19 di Kota Semarang sebanyak 123 orang pada tanggal 20 April 2020 [14], dengan jumlah tersebut merupakan jumlah kasus positif tertinggi di Provinsi Jawa Tengah. Dalam upaya untuk penanganan dan pencegahan terhadap peningkatan kasus infeksi COVID-19, maka diperlukan cara yang tepat dan efektif.

Corona dengan nama ilmiah Severe acute respiratory syndrome coronavirus 2 (SARS-CoV-2) merupakan Semarang dapat diminimalisasi.

jenis coronavirus baru yang dapat ditularkan pada manusia [15]. Rumah sakit rujukan penanganan COVID-19 yang disiapkan oleh pemerintah Republik Indonesia untuk penanganan pasien yang dinyatakan positif terinfeksi COVID-19 di Kota Semarang, berjumlah sembilan rumah sakit rujukan [16]. Lokasi
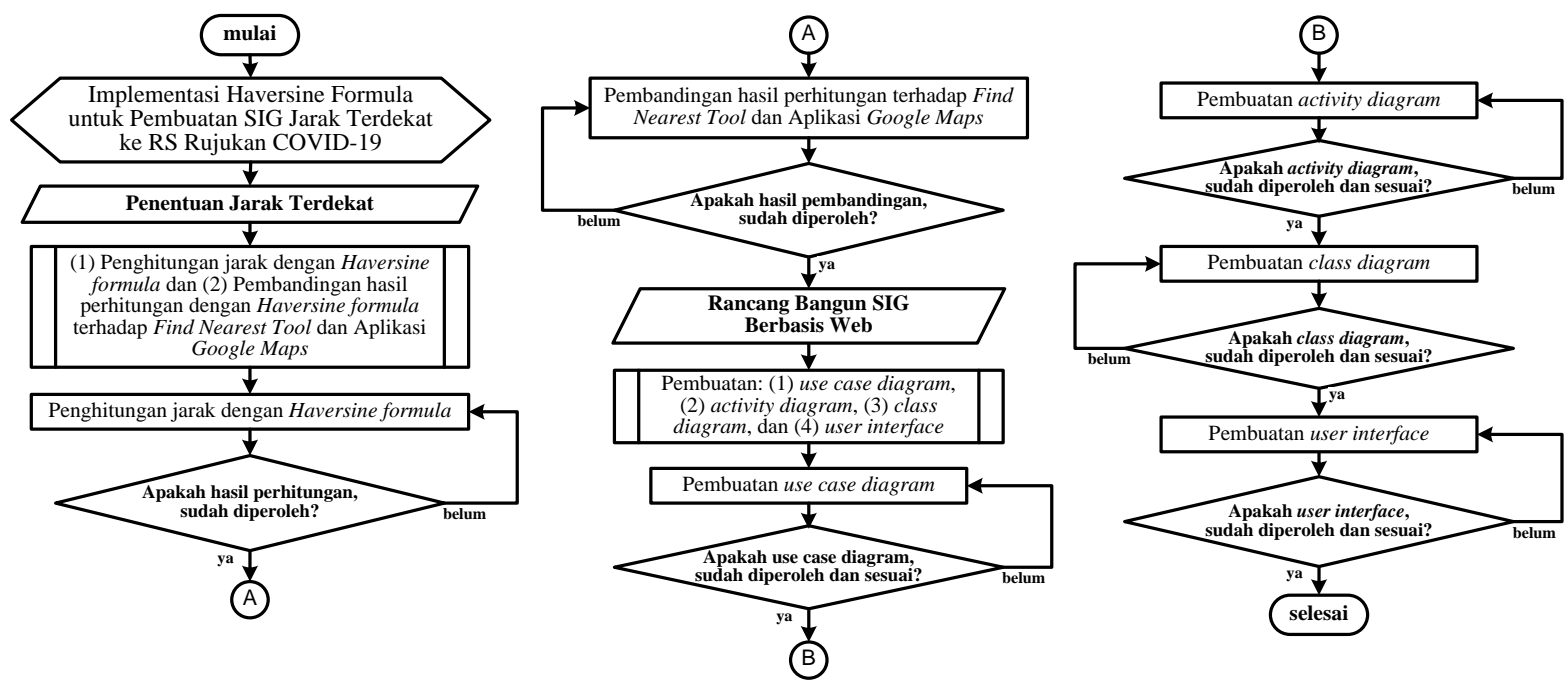

Gambar 2. Diagram alir metode penelitian

Penelitian ini diawali dengan tahap identifikasi masalah. Pengumpulan data dilakukan untuk perolehan data Permasalahan pada penelitian ini, berupa informasi primer dan sekunder. Data primer berupa peta titik awal lokasi rumah sakit rujukan penanganan COVID-19 user dan data sekunder berupa peta administrasi Kota sangat minim, sehingga lokasi masyarakat terhadap Semarang dengan peta titik rumah sakit rujukan keberadaan rumah sakit terdekat tidak diketahui. penanganan COVID-19 di Kota Semarang. Penentuan Keberadaan SIG diperlukan sebagai suatu sistem yang jarak terdekat dilakukan dengan Haversine formula dapat digunakan untuk análisis data spasial maupun non- untuk penghitungan jarak dari titik awal saat user berada, spasial [17]. Kemudahan pada SIG dalam penyajian dan ke tiap rumah sakit rujukan penanganan COVID-19. pencarian informasi terkait jarak untuk tujuan ke rumah Setelah dilakukan perhitungan jarak ke masing-masing sakit rujukan [18].

rumah sakit rujukan, kemudian diperoleh pilihan rumah 
sakit rujukan dengan jarak yang terdekat. Pengukuran Kota Semarang, dimulai dengan titik awal ditentukan ketelitian hasil perhitungan dilakukan dengan berada di Masjid Agung Jawa Tengah yang terletak pada pembandingan terhadap Find Nearest Tool dan aplikasi titik latitude -6.983472 dan titik longitude 110.445139. Google Maps. Find Nearest Tool merupakan aplikasi Algoritma Haversine formula dijelaskan dengan uraian web ArcGIS Online dengan jarak garis digunakan untuk berikut. pengukuran antara fitur masukan (input) dan fitur terdekat [19]. Aplikasi Google Maps merupakan aplikasi navigasi dengan lebih dari satu milyar pengguna setiap bulannya [20] dan ketersediaan fitur untuk pengukuran jarak garis lurus antara dua titik yang ditandai pada peta.

Rancang bangun SIG diawali dengan pembuatan use case, activity, dan class diagram. Diagram-diagram tersebut merupakan bagian dari Unified Modeling Language (UML), yaitu teknik pengembangan sistem dengan bahasa grafis yang digunakan sebagai alat untuk perancangan, visualisasi, dan dokumentasi pada sistem [21]. Tahapan lanjutan berupa perancangan user interface. User interface merupakan aspek dari suatu program yang diperlukan sebagai penghubung antara
user dengan sistem, agar user dapat dengan mudah dalam pengoperasian atau pengolahan data [22].

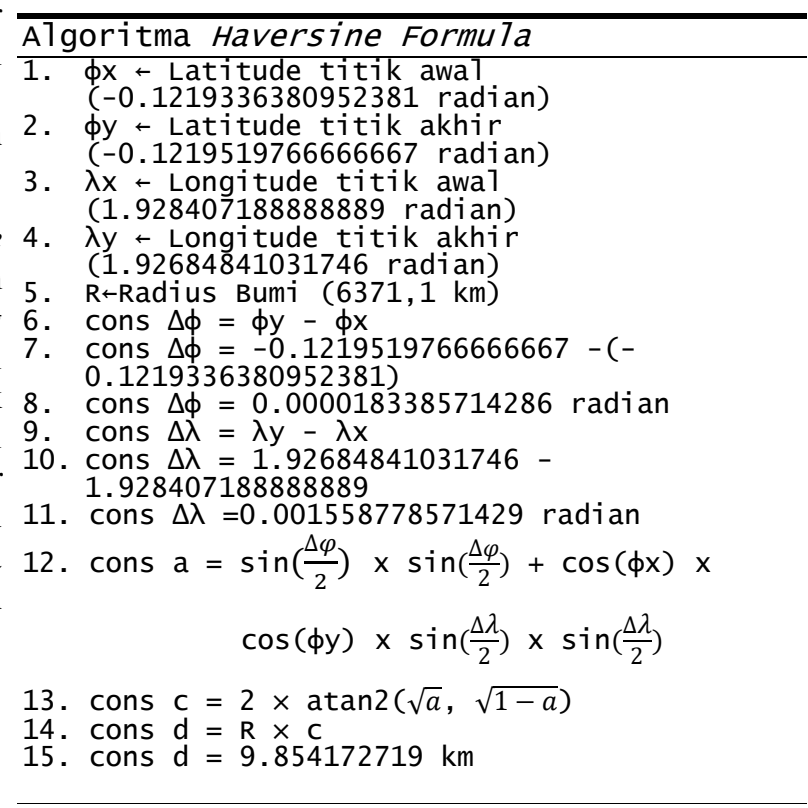

\section{Hasil dan Pembahasan}

\subsection{Penentuan Jarak Terdekat}

Haversine formula diterapkan pada SIG untuk pencarian rumah sakit rujukan penanganan COVID-19 di Kota Semarang sebagai penghitung jarak antara titik awal yang ditentukan oleh user dan titik tujuan ke rumah sakit rujukan. Penentuan rumah sakit rujukan dengan jarak terdekat dilakukan dengan perhitungan jarak dari koordinat titik awal ke sembilan titik koordinat rumah sakit rujukan penanganan COVID-19 di Kota Semarang. Setelah diketahui jarak ke masing-masing rumah sakit rujukan, kemudian hasil tersebut dibandingkan dan dicari jarak dengan nilai terkecil. Rumah sakit rujukan dengan nilai terkecil tersebut dipilih sebagai rumah sakit
rujukan dengan jarak terdekat dari titik awal yang ditentukan oleh user.

3.1.1. Penentuan jarak terdekat dengan penghitungan berbasis Haversine formula

Analisis cara operasi Haversine formula untuk pencarian rumah sakit rujukan penanganan COVID-19 terdekat di
Sebelum dilakukan perhitungan jarak dari kedua titik, pertama-tama perlu dicari selisih latitude dan longitude dari kedua titik (baris 6 dan baris 9). Selisih latitude dan longitude dari kedua titik tersebut digunakan dalam pencarian kalkulasi perpotongan sumbu (baris 13), dan kemudian dilakukan perhitungan untuk penentuan jarak dari kedua titik (baris 14). Berdasarkan algoritma Haversine formula tersebut, diketahui bahwa jarak antara Masjid Agung Jawa Tengah ke RS Tugurejo Semarang sejauh $9,85 \mathrm{~km}$. Perlu dilakukan perhitungan Haversine formula untuk tiap rumah sakit rujukan, agar dapat diketahui rumah sakit rujukan penanganan COVID-19 di Kota Semarang dengan jarak terdekat dari Masjid Agung Jawa Tengah. Hasil perhitungan berbasis Haversine formula untuk tipa RS rujukan, seperti ditunjukkan pada Tabel 1.

Tabel 1. Hasil perhitungan berbasis Haversine formula untuk tiap RS rujukan

\begin{tabular}{llll}
\hline Nama Rumah Sakit & Latitude & Longitude & Jarak dari titik awal (dalam km) \\
\hline RS Bhayangkara Semarang & -7.0001493 & 110.446356 & 1.8593183454979 \\
RS Telogorejo & -6.9877829 & 110.4266337 & 2.09795056170644 \\
RSI Sultan Agung & -6.95559 & 110.4614557 & 3.58550326549514 \\
RS ST. Elisabeth & -7.0082829 & 110.4199202 & 3.91900663224224 \\
RS Bhakti Wira Tamtama & -6.9862694 & 110.4083125 & 4.07647781291803 \\
RSUP Dr. Kariadi & -6.9940501 & 110.4073795 & 4.3303470090272 \\
RSUD K.R.M.T. Wongsonegoro & -7.0339753 & 110.4668256 & 6.10457523409603 \\
RS Columbia Asia Semarang & -6.9842186 & 110.3827548 & 6.88594726554928 \\
RSUD Tugurejo Semarang & -6.9845223 & 110.3558635 & 9.85417271903181 \\
\hline
\end{tabular}

Berdasarkan Tabel 1 ditunjukkan, bahwa dari sembilan terdapat di Kota Semarang, rumah sakit rujukan dengan rumah sakit rujukan penanganan COVID-19 yang jarak terdekat dari Masjid Agung Jawa Tengah, adalah 
RS Bhayangkara Semarang dengan jarak $1,85 \mathrm{~km} ; 3.1 .2$. Pembandingan hasil penghitungan terhadap Find sedangkan rumah sakit rujukan dengan jarak terjauh dari Nearest Tool dan Aplikasi Google Maps

Masjid Agung Jawa Tengah, adalah RSUD Tugurejo Semarang dengan jarak 9,85 km. Perlu diketahui, bahwa dalam penentuan jarak terdekat tersebut, jalur lalu lintas maupun aturan-aturan berkendara yang berlaku tidak diperhatikan, tetapi hanya dilihat jarak berdasarkan garis lurus yang ditarik dari titik awal hingga ke titik tujuan.
Perbandingan pengukuran jarak terdekat dilakukan dengan aplikasi web ArcGIS Online dengan tool berupa Find Nearest Tool untuk pengukuran ketepatan perhitungan dengan Haversine formula. Fungsi tool tersebut sama dengan implementasi Haversine formula, yaitu sebagai penghitung jarak diantara dua titik dan penetapan jarak dengan nilai yang terkecil sebagai jarak terdekat. Perbandingan hasil antara perhitungan Haversine formula dan Find Nearest Tool dari ArcGIS online, seperti ditunjukkan pada Tabel 2.

Tabel 2. Perbandingan hasil antara perhitungan Haversine formula dan Find Nearest Tool dari ArcGIS online

\begin{tabular}{|c|c|c|c|c|c|}
\hline Nama Rumah Sakit & Latitude & Longitude & $\begin{array}{c}\text { Penghitungan dengan } \\
\text { Haversine formula } \\
\text { (dalam km) }\end{array}$ & $\begin{array}{l}\text { Pengukuran dengan } \\
\text { Find Nearest Tool } \\
\text { (dalam km) }\end{array}$ & $\begin{array}{l}\text { Nilai Selisih } \\
\text { (dalam meter) }\end{array}$ \\
\hline RS Bhayangkara Semarang & -7.0001493 & 110.446356 & 1.8593183454979 & 1.84516624624 & 14 \\
\hline RS Telogorejo & -6.9877829 & 110.4266337 & 2.09795056170644 & 2.0950146719 & 3 \\
\hline RSI Sultan Agung & -6.95559 & 110.4614557 & 3.58550326549514 & 3.5640604574 & 21 \\
\hline RS ST. Elisabeth & -7.0082829 & 110.4199202 & 3.91900663224224 & 3.902086231 & 17 \\
\hline RS Bhakti Wira Tamtama & -6.9862694 & 110.4083125 & 4.07647781291803 & 4.07200678556 & 4 \\
\hline RSUP Dr. Kariadi & -6.9940501 & 110.4073795 & 4.3303470090272 & 4.32366732806 & 7 \\
\hline RSUD K.R.M.T. Wongsonegoro & -7.0339753 & 110.4668256 & 6.10457523409603 & 6.06410094578 & 40 \\
\hline RS Columbia Asia Semarang & -6.9842186 & 110.3827548 & 6.88594726554928 & 6.87866034008 & 7 \\
\hline RSUD Tugurejo Semarang & -6.9845223 & 110.3558635 & 9.85417271903181 & 9.8437453709 & 10 \\
\hline
\end{tabular}

Berdasarkan Tabel 2 ditunjukkan, bahwa terdapat Diperoleh nilai rata-rata selisih sebesar 13 meter. sembilan titik terhitung dengan selisih hasil antara Perbandingan hasil perhitungan Haversine formula juga penghitungan dengan Haversine formula dan Find dilakukan terhadap hasil pengukuran jarak pada aplikasi Nearest Tool sebesar 3 meter hingga 40 meter, sehingga Google Maps. Fitur untuk pengukuran jarak garis lurus dilakukan penghitungan nilai rata-rata selisih, yaitu:

Rata-rata selisih $=\frac{\text { Jumlah Selisih }}{\text { Banyak Titik }}$ $=\frac{14+3+21+17+4+7+40+7+10}{9}=\frac{123}{9}=13 . \quad$ pada Tabel 3.

antara dua titik yang ditandai pada peta juga tersedia pada Google Maps. Perbandingan hasil antara Haversine formula dan aplikasi Google Maps, seperti ditunjukkan

Tabel 3. Perbandingan hasil antara perhitungan Haversine formula dan aplikasi Google Maps

\begin{tabular}{|c|c|c|c|c|c|}
\hline Nama Rumah Sakit & Latitude & Longitude & $\begin{array}{c}\text { Penghitungan dengan } \\
\text { Haversine formula } \\
\text { (dalam km) }\end{array}$ & $\begin{array}{c}\text { Pengukuran dengan } \\
\text { aplikasi Google } \\
\text { Maps (dalam km) }\end{array}$ & $\begin{array}{l}\text { Nilai Selisih } \\
\text { (dalam meter) }\end{array}$ \\
\hline RS Bhayangkara Semarang & -7.0001493 & 110.446356 & 1.8593183454979 & 1.86 & 1 \\
\hline RS Telogorejo & -6.9877829 & 110.4266337 & 2.09795056170644 & 2.1 & 2 \\
\hline RSI Sultan Agung & -6.95559 & 110.4614557 & 3.58550326549514 & 3.59 & 4 \\
\hline RS ST. Elisabeth & -7.0082829 & 110.4199202 & 3.91900663224224 & 3.92 & 1 \\
\hline RS Bhakti Wira Tamtama & -6.9862694 & 110.4083125 & 4.07647781291803 & 4.08 & 4 \\
\hline RSUP Dr. Kariadi & -6.9940501 & 110.4073795 & 4.3303470090272 & 4.33 & 0 \\
\hline RSUD K.R.M.T. Wongsonegoro & -7.0339753 & 110.4668256 & 6.10457523409603 & 6.1 & 5 \\
\hline RS Columbia Asia Semarang & -6.9842186 & 110.3827548 & 6.88594726554928 & 6.89 & 4 \\
\hline RSUD Tugurejo Semarang & -6.9845223 & 110.3558635 & 9.85417271903181 & 9.85 & 4 \\
\hline
\end{tabular}

Berdasarkan Tabel 3 ditunjukkan, bahwa terdapat sembilan titik terhitung dengan selisih hasil antara 3.2. Rancang Bangun SIG Berbasis Web penghitungan dengan Haversine formula dan Find Nearest Tool pada kisaran nilai 0 hingga 5 meter, sehingga dilakukan penghitungan nilai rata-rata selisih, yaitu:

$$
\begin{aligned}
& \text { Rata-rata selisih }=\frac{\text { Jumlah Selisih }}{\text { Banyak Titik }} \\
& \quad=\frac{1+2+4+1+4+0+5+4+4}{9}=\frac{25}{9}=3
\end{aligned}
$$

SIG pencarian lokasi rumah sakit rujukan penanganan COVID-19 dapat digunakan oleh masyarakat sebagai bentuk visualisasi peta, agar lebih mudah dipahami oleh user sebagai pengguna sistem. Rancang bangun SIG dilakukan dengan tahapan pembuatan diagram use case, activity, dan class yang dilanjutkan dengan pembuatan user interfase.

Diperoleh nilai rata-rata selisih sebesar 3 meter.

\subsubsection{Diagram use case}

Diagram use case digunakan untuk visualisasi aktivitas yang dapat dilakukan oleh user sebagai pengguna sistem dan administrator sebagai pengelola sistem, sehingga 
SIG pencarian lokasi rumah sakit rujukan penanganan Diagram use case untuk user dan administrator, seperti COVID-19 terdekat di Kota Semarang dapat digunakan. ditunjukkan Gambar 3.

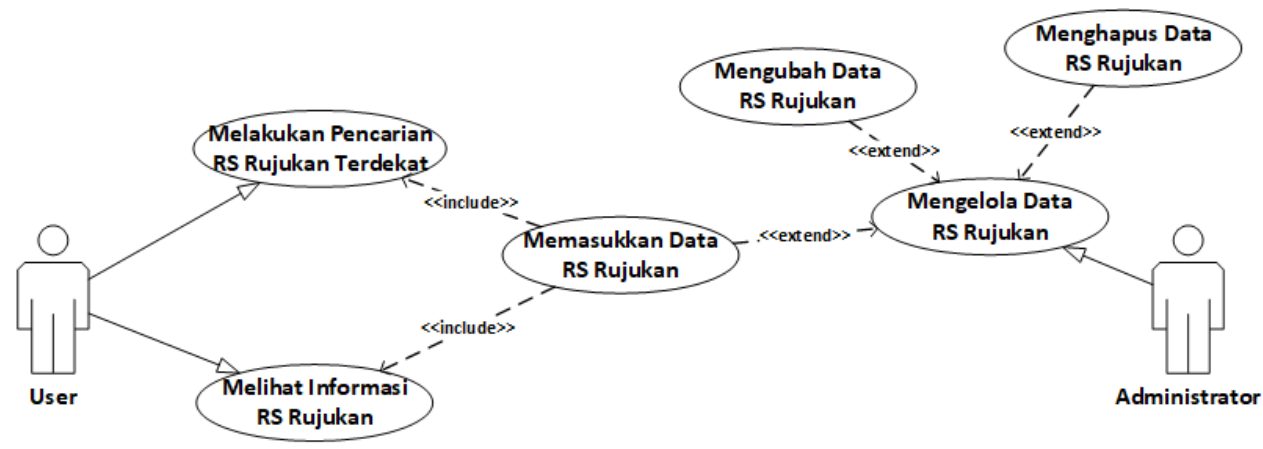

Gambar 3. Diagram use case untuk user dan administrator

Berdasarkan Gambar 3 ditunjukkan, bahwa aktivitas dahulu oleh administrator, kemudian divalidasi oleh yang dapat dilakukan oleh user sebagai pengguna sistem, sistem. Untuk kondisi dimana login berhasil divalidasi, adalah pencarian rumah sakit rujukan terdekat dan maka ditampilkan menu utama dari SIG pencarian informasi dari rumah sakit rujukan penanganan COVID- rumah sakit rujukan penanganan COVID-19 di Kota 19 tersebut juga dapat dilihat oleh user. Pengelolaan data Semarang. rumah sakit rujukan penanganan COVID-19 dilakukan administrator sebagai pengelola sistem, yaitu pemasukan, pengubahan, maupun penghapusan data rumah sakit rujukan penanganan COVID-19.

\subsubsection{Diagram activity}

Diagram activity digunakan sebagai visualisasi urutan aktivitas dalam suatu proses. Terdapat tiga diagram activity yang digunakan dalam SIG pencarian lokasi rumah sakit rujukan penanganan COVID-19, yaitu diagram pengelolaan data rumah sakit rujukan yang dilakukan oleh administrator, diagram pencarian lokasi rumah sakit rujukan terdekat yang dilakukan oleh user, dan diagram pencarian informasi rumah sakit rujukan yang dilakukan oleh user. Diagram pengelolaan data rumah sakit rujukan penagnan CoViD-19, seperti ditunjukkan pada Gambar 4.

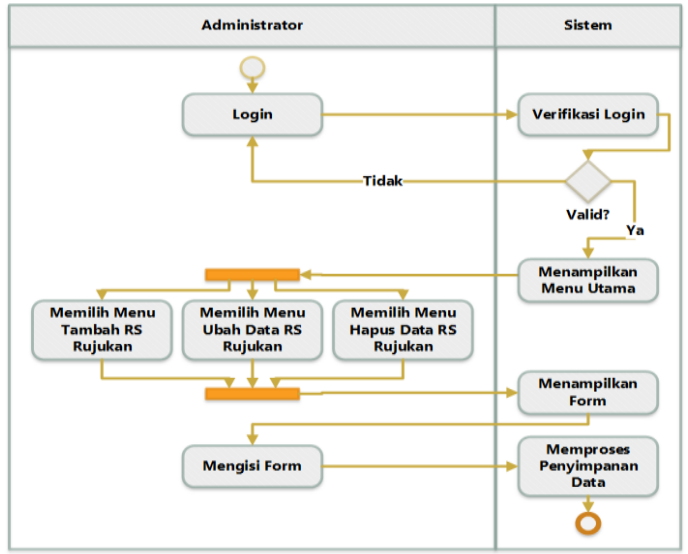

Gambar 4. Diagram pengelolaan data rumah sakit rujukan penanganan CoViD-19
Setelah salah satu menu yang telah tersedia telah dipilih oleh administrator, form sesuai dengan menu yang telah dipilih ditampilkan. Setelah itu, form tersebut diisi oleh administrator dan kemudian dilakukan penyimpan penambahan, perubahan, atau penghapusan data rumah sakit rujukan penanganan COVID-19, sesuai dengan data yang telah diisi oleh administrator. Diagram pencarian lokasi rumah sakit rujukan terdekat, seperti ditunjukkan pada Gambar 5.

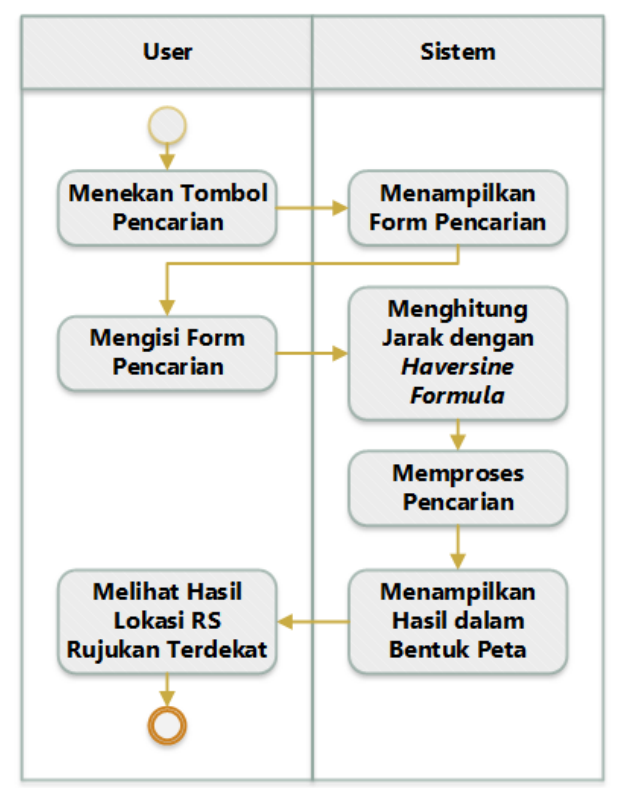

Gambar 5. Diagram pencarian lokasi rumah sakit rujukan terdekat

Berdasarkan Gambar 5 ditunjukkan, bahwa alur aktivitas yang dilakukan oleh user dalam pencarian rumah sakit rujukan dengan lokasi terdekat. PertamaBerdasarkan Gambar 4 ditunjukkan, bahwa sebelum tama, dilakukan penekanan pada tombol pencarian masuk ke dalam sistem, perlu dilakukan login terlebih terlebih dahulu untuk mulai pencarian rumah sakit 
rujukan terdekat. Setelah tombol pencarian ditekan oleh ditekan oleh user, sehingga dapat dilihat daftar rumah user, form pencarian yang harus diisi oleh user sakit rujukan yang terdapat pada sistem. Setelah daftar ditampilkan oleh sistem. Terdapat text field yang perlu rumah sakit rujukan ditampilkan oleh sistem, dapat diisi dengan alamat oleh user, karena alamat tersebut dilihat berbagai informasi dari tiap rumah sakit rujukan dijadikan sebagai titik awal dalam pencarian rumah sakit penanganan COVID-19 di Kota Semarang. Informasi rujukan terdekat. Setelah alamat diketikkan oleh user, yang dapat diperoleh oleh user berupa nama, alamat jarak dari alamat yang diisikan oleh user sebagai titik lengkap, dan nomor telepon dari rumah sakit rujukan awal ke setiap rumah sakit rujukan penanganan COVID- yang telah dipilih.

19 dihitung oleh sistem. Selanjutnya ditentukan lokasi

rumah sakit rujukan dengan jarak terdekat dari titik awal 3.2.3. Diagram class

dan ditampilkan ke user hasil pencarian lokasi rumah Diagram class pada SIG pencarian rumah sakit rujukan sakit rujukan terdekat tersebut dalam bentuk peta penanganan CoViD-19 di Kota Semarang, seperti interaktif.

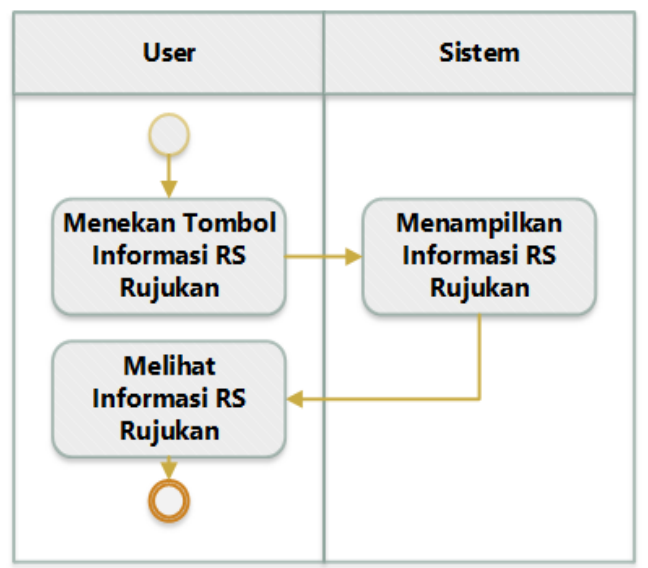

Gambar 6. Diagram pencarian informasi rumah sakit rujukan

Tahapan pencarian informasi rumah sakit rujukan penanganan COVID-19 dapat dilihat pada Gambar 6. Pertama-tama tombol daftar rumah sakit rujukan perlu

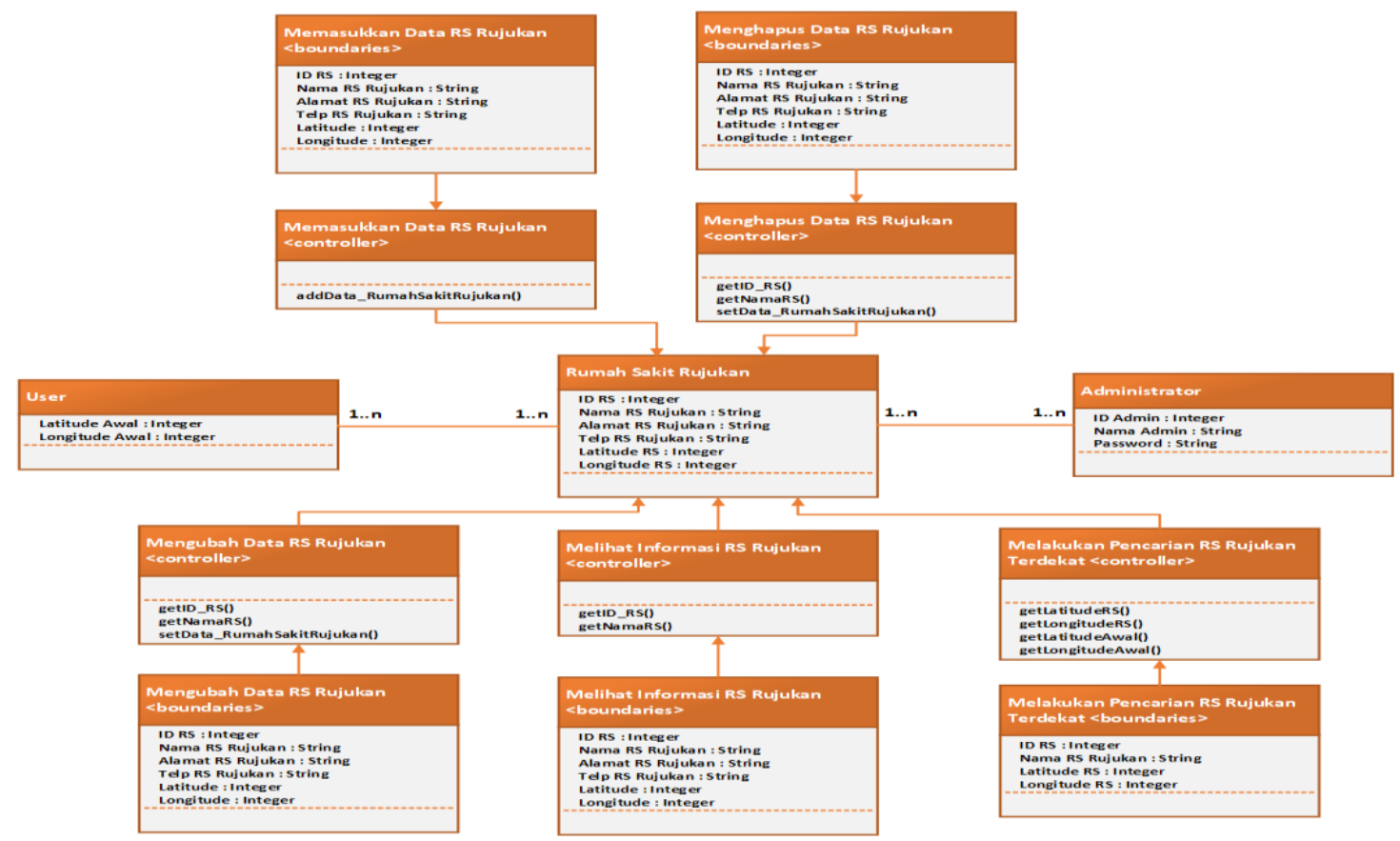

Gambar 7. Diagram class pada SIG pencarian rumah sakit rujukan penanganan CoViD-19 


\subsubsection{Pembuatan user interface}

Kebutuhan user terhadap sistem dalam pelaksanaan user interface, agar user dapat kemuudahan dalam pemahaman dan penggunaan SIG pencarian rumah sakit rujukan penanganan COVID-19 terdekat di Kota Semarang. Terdapat dua user interface utama yang digunakan dalam sistem pencarian rumah sakit rujukan, yaitu interface oleh user sebagai pengunjung dari sistem dan interface oleh administrator sebagai pengelola sistem.

Sebelum masuk ke dalam sistem, perlu dilakukan login terlebih dahulu oleh administrator, dengan pengisian username dan password yang telah terdaftar pada database. Keamanan ini diperlukan untuk pencegahan adanya akses dari pihak-pihak yang tidak bertanggung jawab, sehingga ancaman terhadap sistem dapat diminimalisasi. Sistem dapat diakses oleh administrator setelah username dan password telah tervalidasi dengan benar. Tampilan interface utama dari SIG pencarian rumah sakit rujukan penanganan COVID-19 di Kota Semarang untuk administrator, seperi ditunjukkan pada Gambar 8 .

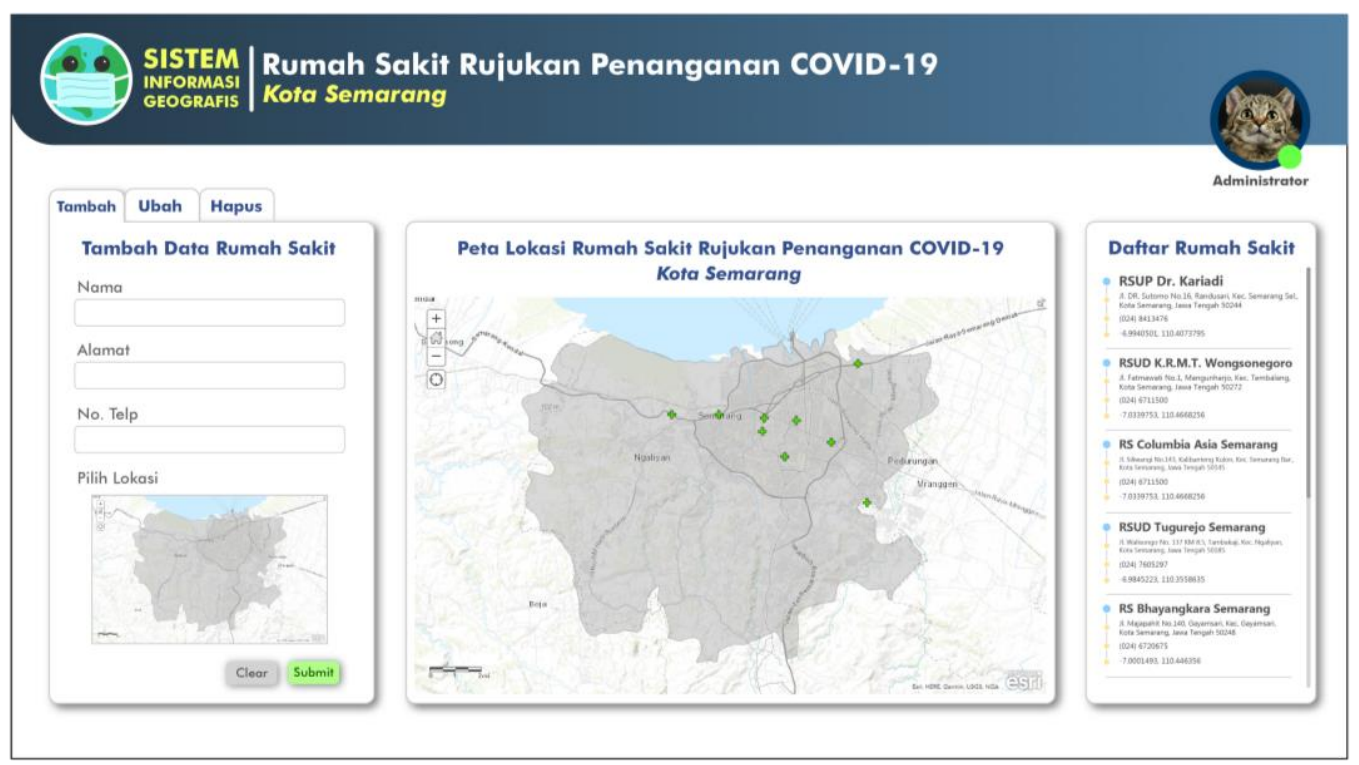

Gambar 8. Tampilan interface utama dari SIG pencarian rumah sakit rujukan penanganan COVID-19 di Kota Semarang untuk administrator

Peta interaktif lokasi rumah sakit rujukan penanganan dapat dipilih oleh user, yaitu menu Informasi Rumah COVID-19 yang tersebar di Kota Semarang dapat dilihat Sakit Rujukan dan menu Cari Rumah Sakit Rujukan oleh administrator pada interface utama. Peta tersebut Terdekat. User tidak perlu login terlebih dahulu, agar adalah peta interaktif yang dapat dijelajahi dengan sistem dapat diakses oleh user. Tampilan interface dilakukannya zoom in dan zoom out pada peta, sehingga informasi pencarian rumah sakit rujukan penanganan lokasi rumah sakit rujukan dapat dilihat dengan lebih COVID-19 di Kota Semarang untuk user, seperti detail. Terdapat daftar rumah sakit rujukan pada sisi ditunjukkan pada Gambar 9.

kanan interface, dengan informasi yang lengkap dari tiap rumah sakit, yaitu berupa nama rumah sakit, alamat rumah sakit, nomor telepon rumah sakit, dan koordinat rumah sakit. Terdapat tiga menu yang dapat dipilih oleh administrator pada interface di sisi kiri, yaitu menu untuk penambahan data rumah sakit rujukan baru, menu untuk pengubahan pada data eksisting rumah sakit rujukan dalam database, dan menu untuk penghapusan data eksisting rumah sakit rujukan dalam database. Terdapat menu profil yang dapat digunakan untuk logout dari sistem pada sisi kanan atas dari tampilan interface utama.

Berdasarkan Gambar 9 ditunjukkan, bahwa interface yang dimunculkan saat menu informasi rumah sakit rujukan dipilih oleh user. Informasi tentang rumah sakit rujukan penanganan COVID-19 di Kota Semarang dapat dilihat oleh user pada menu ini. Sama seperti pada interface untuk administrator, terdapat peta interaktif lokasi rumah sakit rujukan penanganan COVID-19 yang tersebar di Kota Semarang. Peta tersebut dapat dijelajahi untuk penglihatan dengan lebih detail lokasi rumah sakit rujukan di Kota Semarang. Terdapat daftar rumah sakit rujukan di Kota Semarang dengan informasi detail tentang rumah sakit rujukan tersebut pada sisi kanan dari Saat sistem diakses oleh user, akan terlihat tampilan interface. Tampilan interface cari rumah sakit rujukan interface utama, dimana terdapat dua pilihan menu yang terdekat, seperti ditunjukkan pada Gambar 10. 


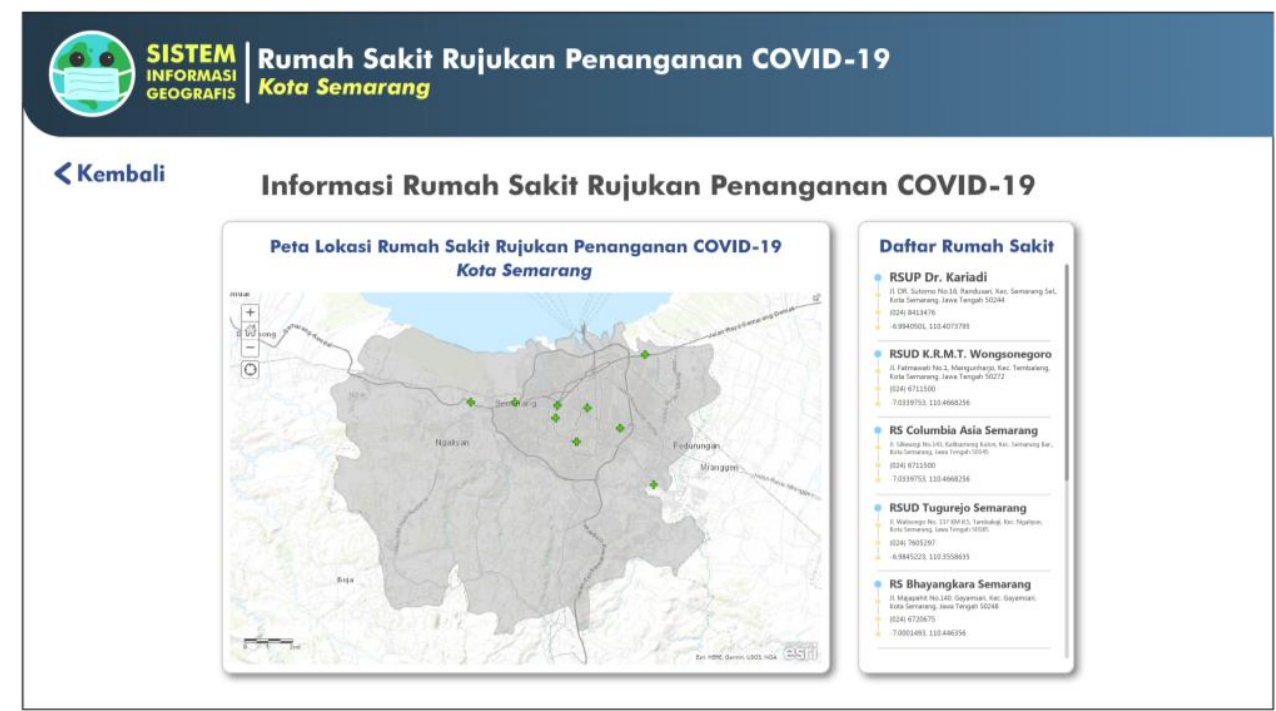

Gambar 9. Tampilan interface informasi pencarian rumah sakit rujukan penanganan COVID-19 di Kota Semarang untuk user

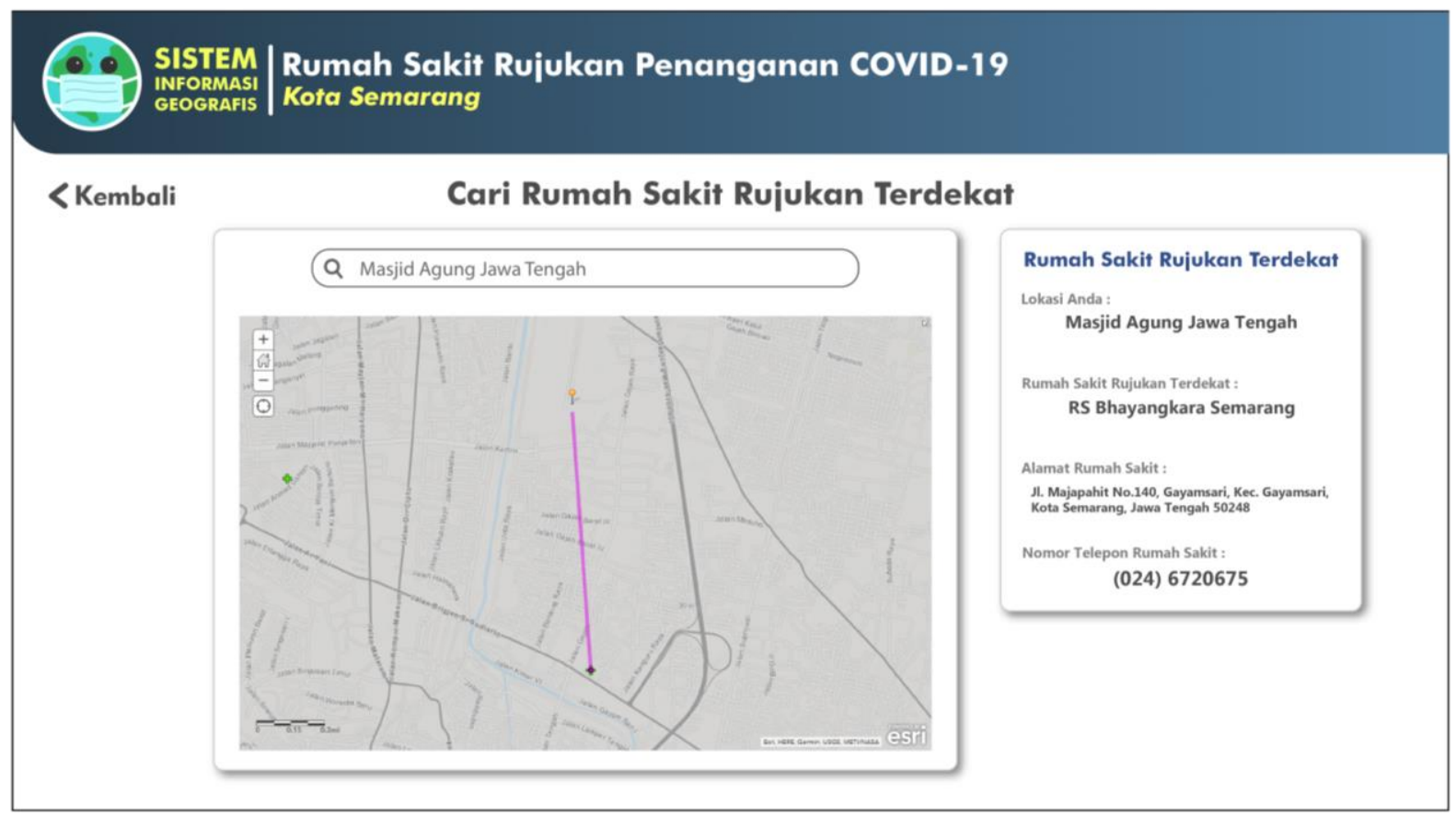

Gambar 10. Tampilan interface cari rumah sakit rujukan terdekat

Berdasarkan Gambar 10 ditunjukkan, bahwa interface tersebut kemudian ditampilkan dalam bentuk peta cari rumah sakit rujukan terdekat dimunculkan, jika interaktif sebagaimana ditunjukkan pada Gambar 10. menu Cari Rumah Sakit Rujukan Terdekat dipilih oleh Penunjukan informasi tentang lokasi user sesuai dengan user. Pencarian rumah sakit rujukan dengan lokasi alamat yang dimasukkan, beserta informasi rumah sakit terdekat dari alamat yang dimasukkan oleh user dapat rujukan dengan jarak terdekat sesuai dengan hasil dilakukan pada menu ini. Tahapan dalam pencarían, pencarían, terletak pada sisi kanan pada tampilan yaitu pertama-tama alamat yang diinginkan sebagai interface.

lokasi user berada perlu dimasukkan terlebih dahulu oleh user. Pencarian koordinat dari alamat yang telah dimasukkan oleh user dilakukan oleh sistem. Setelah koordinat berhasil ditemukan, perhitungan dengan Haversine formula dilakukan oleh sistem untuk pencarian rumah sakit rujukan dengan jarak terdekat dari

\section{Kesimpulan}

Berdasarkan hasil dan pembahasan, maka dapat ditarik kesimpulan sesuai tujuan penelitian. Penerapan Haversine formula dapat digunakan untuk perhitungan jarak dari titik awal lokasi user dengan tujuan rumah 
sakit rujukan, namun terdapat selisih hasil perhitungan, jika dibandingkan terhadap Find Nearest Tool maupun aplikasi Google Maps. Perbandingan terhadap Find Nearest Tool diperoleh nilai selisih rata-rata sebesar 13 meter, dengan selisih terkecil 3 meter dan terbesar 40 meter, sedangkan perbandingan terhadap pengukuran jarak garis lurus berbantuan aplikasi Google Maps diperoleh nilai selisih rata-rata sebesar 3 meter, dengan selisih terkecil 0 meter dan terbesar 5 meter.

Rancang bangun SIG juga berhasil dilakukan melalui perancangan use case diagram, activity diagram, class diagram, serta perancangan user interface. Berdasarkan hasil tersebut dapat disimpulkan, bahwa pembuatan SIG berbasis Haversine formula dapat digunakan sebagai "Sistem Informasi Geografis Pencarian Rumah Sakit Rujukan Penanganan COVID-19 di Kota Semarang" berdasarkan jarak terdekat dari lokasi user.

\section{Daftar Rujukan}

[1] R. A. Azdy and F. Darnis, "Implementasi Bellman-Ford untuk Optimasi Rute Pengambilan Sampah di Kota Palembang," J. Nas. Tek. Elektro dan Teknol. Inf., vol. 8, no. 4, p. 327, 2019, doi: 10.22146/jnteti.v8i4.532.

[2] R. H. D. Putra, H. Sujiani, and N. Safriadi, "Penerapan Metode Haversine Formula Pada Sistem Informasi Geografis Pengukuran Luas Tanah," J. Sist. dan Teknol. Inf., vol. 10, no. 2, pp. 1262 1270, 2015.

[3] Y. Yulianto, R. Ramadiani, and A. H. Kridalaksana, "Penerapan Formula Haversine Pada Sistem Informasi Geografis Pencarian Jarak Terdekat Lokasi Lapangan Futsal," Inform. Mulawarman J. Ilm. Ilmu Komput., vol. 13, no. 1, p. 14, 2018, doi: [22] 10.30872/jim.v13i1.1027.

[4] N. Panigrahi, Computing in geographic information systems. 2014.

[5] C. Veness, "Calculate distance and bearing between two Latitude/Longitude points using haversine formula," MIT Open Source, 2019.2 https://www.movabletype.co.uk/scripts/latlong.html (accessed Sep. 23, 2020).

[6] P. Harsadi and D. Nugroho, "Implementasi Algoritma Dijkstra Dan Metode Haversine Pada Penentuan Jalur Terpendek Pendakian Gunung Merapi Jalur Selo Berbasis Android," $J$. Teknol. Inf. dan Komun., vol. 8, no. 1, pp. 61-67, 2020, doi: 10.30646/tikomsin.v8i1.483.

[7] N. Chopde and M. Nichat, "Landmark Based Shortest Path Detection by Using A* and Haversine Formula," GH Raisoni Coll. Eng. ..., vol. 1, no. 2, pp. 298-302, 2013, [Online]. Available:

http://www.ijircce.com/upload/2013/april/17_V1204030_Landm ark_H.pdf.

[8] M. A. Nur and N. Wardhani, "Penerapan Formula Faversine dalam Perhitungan Luas WilayahMenggunakan Koordinat Google Maps," J. IT, vol. 9, no. 1, pp. 58-64, 2018.

[9] P. Dauni, M. D. Firdaus, R. Asfariani, M. I. N. Saputra, A. A. Hidayat, and W. B. Zulfikar, "Implementation of Haversine formula for school location tracking," in Journal of Physics: Conference Series, 2019, vol. 1402, no. 7, doi: 10.1088/1742$6596 / 1402 / 7 / 077028$

[10] K. M. Wibowo, K. Indra, and J. Jumadi, "Sistem Informasi Geografis (SIG) Menentukan Lokasi Pertambangan Batu Bara di Provinsi Bengkulu Berbasis Website,' J. Media Infotama, vol. 11, no. 1, pp. 51-60, 2015, [Online]. Available: https://jurnal.unived.ac.id/index.php/jmi/article/view/252/231.

[11] T. Wuryandari, A. Hoyyi, D. S. Kusumawardani, and D. Rahmawati, "Identifikasi Autokorelasi Spasial Pada Jumlahpengangguran Di Jawa Tengah Menggunakan Indeks Moran," Media Stat., vol. 7, no. 1, pp. 1-10, 2014, doi: 10.14710/medstat.7.1.1-10.

2] L. P. A. Prapitasari, N. K. Sumiari, and N. K. D. A. Jayanti, "Sistem Informasi Geografis Pasar Tradisional di Wilayah Denpasar menggunakan Framework YII," Sisfotenika, vol. 6, no. 2, pp. 205-216, 2016, doi: 10.30700/jst.v6i2.118.

13] Badan Pusat Statistik(BPS), Badan pusat statistik kota Semarang. 2019.

[14] P. K. Semarang, "Covid-19 Kota Semarang," https://siagacorona.semarangkota.go.id/, 2020. https://siagacorona.semarangkota.go.id/ (accessed Sep. 23, 2020).

[15] World Health Organization, "Q\&A on coronaviruses (COVID19)," Who, 2020. https://www.who.int/emergencies/diseases/novel-coronavirus2019/question-and-answers-hub/q-a-detail/q-a-coronaviruses (accessed Sep. 23, 2020).

16] "Bertambah, Ini Daftar 58 Rumah Sakit Rujukan Penanganan Virus Corona di Jawa Tengah." https://www.kompas.com/tren/read/2020/03/15/165652365/berta mbah-ini-daftar-58-rumah-sakit-rujukan-penanganan-viruscorona-di-jawa (accessed Sep. 23, 2020).

17] Syafri, S. H., "Identifikasi Kemiringan Lereng di Kawasan Permukiman Kota Manado Berbasis SIG," Spasial, vol. 1, no. 1, pp. 70-79, 2015.

[18] Hermawan, T.A., Nugraha, A.L. and Sudarsono, B., "Desain dan Visualisasi Kampus Universitas Diponegoro Berbasis WebGIS," J. Geod. Undip, vol. 3, no. Januari, pp. 141-154, 2015.

9] "Find Nearest-ArcGIS Online Help | Documentation." https://doc.arcgis.com/en/arcgis-online/analyze/find-nearest.htm (accessed Sep. 23, 2020).

[20] E. Russell, "9 things to know about Google's maps data: Beyond the Map | Google Cloud Blog," 2019. https://cloud.google.com/blog/products/maps-platform/9-thingsknow-about-googles-maps-data-beyond-map (accessed Sep. 23, 2020).

1] S. Mulyani, "Pengertian Activity Diagram," in Analisis dan Perancangan Sistem Informasi Manajemen Keuangan Daerah: Notasi Pemodelan Unified Modeling Language (UML), 2016.

22] E. N. Jannah, A. Hidayah, and M. Mas’ud, "Sistem Terintegrasi Berbasis Web untuk Pencarian dan Pemesanan Kelompok Seni Pertunjukan," J. Nas. Tek. Elektro dan Teknol. Inf., vol. 5, no. 4, 2016, doi: 10.22146/jnteti.v5i4.270. 